\title{
Responsibility versus sustainability, ethics, and societal engagement
}

The German Science, Technology, Innovation context

\author{
Miltos Ladikas, Institute for Technology Assessment and Systems Analysis (ITAS), Karlsruhe Institute of Technology (KIT), \\ Schliemannstraße 46, 10437 Berlin (miltos.ladikas@kit.edu) (1) https://orcid.org/0000-0001-7958-8975 \\ Julia Hahn, Institute for Technology Assessment and Systems Analysis (ITAS), Karlsruhe Institute of Technology (KIT) (julia.hahn@kit.edu) \\ (1) https://orcid.org/0000-0003-2864-7351 \\ Leonhard Hennen, Institute for Technology Assessment and Systems Analysis (ITAS), Karlsruhe Institute of Technology (KIT) \\ (leonhard.hennen@kit.edu) \\ Constanze Scherz, Institute for Technology Assessment and Systems Analysis (ITAS), Karlsruhe Institute of Technology (KIT) \\ (constanze.scherz@kit.edu) (1) https://orcid.org/0000-0003-4488-439x
}

We examine the concept of responsible research and innovation (RRI) in Germany in the context of national science, technology and innovation (STI) as well as its legal and normative framework in relation to ethics and societal engagement and compare the results to similar international research. Our analysis shows that responsibility plays a central role in research practice guided by research ethics standards and societal grand challenges. Consequently, there is a significant increase in demands for inclusion and engagement of a wider stakeholder spectrum in STI. Compared to other countries, the concept of RRI in Germany is increasingly superseded by that of sustainability. We argue that responsibility and sustainability are conceptually close and highly interchangeable in the German national debate. We conclude with basic recommendations for greater clarity in research on responsibility and sustainability and the aims of ethics and societal engagement.

\section{Verantwortung, Ethik und gesellschaftliche Partizipation}

Der deutsche Wissenschafts-, Technologie-, Innovationskontext

Im Folgenden wird das Konzept "Responsible Research and Innovation" (RRI) im Kontext nationaler Forschung, Technologie und Innovation (FTI) sowie seiner rechtlichen und normativen Rahmen in Bezug auf Ethik und gesellschaftliche Partizipation untersucht und mit Erkenntnissen internationaler Forschung verglichen. Die Ergebnisse zeigen, dass Verantwortung eine zentrale Rolle in einer Forschungspraxis einnimmt, die auf forschungsethische Standards und große gesellschaftliche Heraus-

This is an article distributed under the terms of the Creative Commons Attribution License CCBY 4.0 (https://creativecommons.org/licenses/by/4.0/)

https://doi.org/10.14512/tatup.29.3.64

Submitted: 05. 06.2020. Peer reviewed. Accepted: 25.10.2020 forderungen ausgerichtet ist. Forderungen nach Einbeziehung und Partizipation eines breiteren Stakeholder-Spektrums in FTI nehmen daher deutlich zu. Im Vergleich zu anderen Ländern zeigt sich, dass das RRIKonzept in Deutschland jedoch zunehmend durch das der Nachhaltigkeit verdrängt wird. Wir argumentieren, dass Verantwortung und Nachhaltigkeit in der deutschen Debatte konzeptionell nahe beieinander liegen und häufig austauschbar sind. Der Beitrag schließt mit grundlegenden Handlungsempfehlungen für mehr Klarheit in der Forschung zu Verantwortung und Nachhaltigkeit sowie den Zielen von Ethik und gesellschaftlicher Partizipation.

Keywords: responsible research and innovation, ethics, engagement, science-technology-innovation, sustainability

\section{Introduction}

In the last decade, the European debates on social responsibility and accountability in science, technology and innovation (STI) have been dominated by the concept of responsible research and innovation (RRI). It represents the latest attempt to align STI developments with societal expectations. The European Commission has described RRI as a cross-cutting issue in its recent research framework programme Horizon 2020 by defining five RRI keys: Gender, Open Access, Science Education, Ethics, and Public Engagement (EC 2020). The original and most influential conceptualisation of RRI focuses on the process of establishing responsibility, by highlighting core dimensions such as anticipation (i.e. impact of research), reflexivity (i. e. discussions 
on ethical and societal roles and functions), inclusiveness (i. e. stakeholder invitation to discussions) and responsiveness (i. e. policy reaction to RRI demands) (Stilgoe et al. 2013).

In order to understand RRI and the concept of responsibility as part of the national STI system, one needs to assess it not only within the national context itself but also in comparison to other national systems. As part of the European Commission funded project Responsible Research and Innovation in Practice (RRI-PRACTICE), research into aspects of responsibility in STI was undertaken in a total of 12 countries. Following similar research protocols in every country, the German analysis presented here concentrated on the embedment of RRI in national research structures (NR Germany).

The reflections in the present paper make use of national reports issued in 2019 by RRI-PRACTICE on the relevance of RRI keys and dimensions in national research and research policy landscapes and in responsible research performing and research funding organisations. The countries covered are Australia, China, France, Germany, India, Netherlands, Norway, and the United Kingdom. In the RRI practice project the information and insights available from these reports have been studied in a comparative perspective in order to identify the overall state and understanding of responsibility in research and innovation. The results of these comparative ambitions are reports dealing with comparisons for the 5 RRI keys. These are complemented by a report on the integration of the dimensions (inclusiveness, re- in the table we collected material for the German national report and other papers of the RRI-Practice project documenting the results of analysis in the respective country. The material has been read independently by the authors. The structured findings have been compared and discussed and a consensual decision on the assignment of findings has been reached.

\section{The context for RRI: values in Germany's STI strategy}

The identification of values that relates to STI developments in Germany is influenced by the Charter of Fundamental Rights and the European Union Treaty of Lisbon, as is the case with every other European Union member state. These values are Citizens' rights, equality, justice, freedom, and solidarity, the application of which affects also the area of STI (Schroeder and Rerimassie 2015, p.53.). There are various national STI documents that provide the chance to identify such culturally embedded values in practice. Paradigmatic ones are the French Assemblée Nationale's "resolution on science and progress in the French Republic" (French National Assembly 2017), or the Norway Research Council's "strategy for innovation in the public sector" (Norway Research Council 2015). In Germany, the High-TechStrategy (HTS), presents the broad vision of STI². The HTS is the main document to lead public research and innovation, also

\section{In Germany, sustainability is often connected to the idea of responsibility towards future generations.}

sponsivity, reflexivity and anticipation) in research and research management practice, and a report dealing with interactions or mutual influence of concepts and practices regarding the RRI keys. In this paper, reference to national reports is given by "NR" followed by the name of the country. ${ }^{1}$.

In the context of the project RRI-practice, research in Germany and other countries involved a national workshop with 10 to 15 stakeholders in national research policy, two focus groups (5-7 participants) with researchers and administrative and management staff of research and research funding organisations, and five interviews with researchers and research management. The semi-structured interviews covered questions on the understanding of responsibility in the resp. organisation, relevant organisational programmes and activities, the state of implementation of RRI keys and dimensions, as well as questions about the perceived drivers and barriers of RRI related activities in the organisation. The research was conducted in spring and summer 2017. For identifying and evaluating the activities represented

1 All national reports cited in this paper are available online, see the note below the manuscript. mentioning the importance of research on the social implications of STI. The current HTS from 2014 provides a good representation of the strategic priorities in Germany and their connection to political and cultural values. The main challenges and topics the current HTS addresses are: digital economy and society, sustainable economy and energy, the innovative workspace, healthy living, intelligent mobility and civil security (BMBF 2014 , p. 5). These are regarded as holding high innovation potential as well as dealing with (global) challenges and future well-being. In this way, these foci tie the need for research and innovation to the future prosperity and quality of life in Germany. Here, the close connection of the development and public funding of STI and the societal goals of enhancing well-being, prosperity and growth, show clearly. These thematic priorities and subsequent societal benefits are shared widely with the European neighbours (see for instance the notion of " 21 processes" in NR Norway p. 12) but also with key emerging STI-

2 The Ministry provides an English version of the strategy from 2014 here: https://www.hightech-strategie.de/de/The-new-High-Tech-Strategy-390.php. The High-Tech-Strategy as a tool has been implemented for around 10 years. 
based economies (see description of Neruhvian approach to STI in NR India p. 20).

Next to the thematic priorities, a further key part of the HTS is the emphasis on inclusion where the underlying values of a democratic, open society can be found. Next to the procedural aspects of providing a creative ground for the flourishing of innovation, the HTS highlights the need for widened ideas of innovation: "We are emphasising an expanded concept of innovation that includes not only technological innovation but also social innovation - and that includes society as a central player" (BMBF 2014 , p. 4). The inclusion of citizens in STI developments is seen as a way towards improved innovations that are widely accepted within society. The HTS describes plans to enable citi- (e. g. supply and acquisition). The project links sustainability to issues in the context of responsibility in research and provides best practices as well as orientation questions revolving around inter- and transdisciplinarity, inclusion and participation, unintended impacts or uncertainties for researchers during their work. As such, LeNa is an important project showing the growing importance of sustainability within the German research context.

Overall in Germany, sustainability is often also connected to the idea of responsibility towards future generations. For instance, the energy transition or the highly contested discussions on nuclear waste disposal are often debated in the context of Sustainability. This is a unique characteristic in the German STI-focused debates, whereby sustainability has become inter-

\section{Responsibility of research is about pursuing the aims of society ensured by constant exchange with societal actors.}

zens to help shape innovation policy and it plans to improve its information provision regarding new technologies (BMBF 2014, p. 45). The move towards more inclusion, although often vague in terms of formats or its incorporation in the political system, can be seen as a way to increase the legitimacy and acceptance of STI policies. This aspiration is widely shared amongst all participants in RRI Practice regardless whether their national policy system is amenable to inclusion (e.g. in The Netherlands) or not (e.g. in China). In every case, inclusion is described as an indispensable part of national STI developments (NR China; NR Netherlands).

Although the fundamental rights of individuals and their dignity, as stated in the first paragraph of the German Constitution as well as the European values of freedom, citizens' rights, justice, equality, are clearly identified in documents such as the HTS, the concept of sustainability also shows tremendous traction. Over the past decades the German socio-political landscape has been highly influenced by sustainability, which has in turn shaped the STI discussions. This has also influenced research organisations, which have put issues of sustainability on their scientific agendas (e. g. focusing on climate change or advancements in energy or mobility) as well as aiming at integrating it on organisational levels. For instance, the LeNa project (Sustainability Management for Non-University Research Organisations) was a collaboration of the biggest research organisations in Germany - Helmholtz, Fraunhofer and the Leibniz Association - and developed a manual with sustainability guidelines for these organisations (LeNa Project 2016). LeNa focused on several areas within these organisations such as the management and strategic level (e.g. compliance, integrative planning), research (e. g. good practice, societal responsibility, contributing to solving grand challenges), personnel (e.g. service oriented management, networking and cooperation), infrastructure (e. g. operation and management, removal and disposal) and support twined with the understanding of responsibility and has resulted in concrete incorporation tools (e.g. for industry standards). It has brought to life a variety of local or regional initiatives that try to re-shape how development or progress are understood. One example of this is the ITAS project "Quartier Zukunft", a local urban initiative to make a city quarter more sustainable in a wider and transdisciplinary sense including consumption patterns, or economic and social aspects (Quartier Zukunft et al. 2020). Although the notion of Sustainability is internationally accepted as national priority in our samples, it is only Germany that has a direct relationship to responsibility (Ladikas et al.).

\section{Ethics and societal engagement in the national context}

The analysis shows widespread awareness and agreement in the view that researchers and research organisations have certain responsibilities regarding society. It is an interesting aspect that the overall content of responsibility revolves around the need of research and science to communicate and interact with society, with the goal of bringing the aims of science and those of society closer together. There is importance given to receiving feedback from society in STI but there is also clear criticism of the current standard research practice, that focuses on negative challenges instead on a positive concept of responsibility.

\section{The concept of responsibility}

From the analysis of the documents and the discussions, we deduce the development of at least two different understandings of Responsibility. First, responsibility is perceived as being responsible towards society and also as a critique of research without limits or boundaries (e.g. NR Netherlands). This implies that the Responsibility of research is about pursuing the aims of society 
and ensuring this by a constant exchange with societal actors. Second, responsibility is about how research is conducted in order to ensure a certain standard and progress (e.g. NR China). This understanding is seen in contrast (or to a certain degree opposed) to the demands for more responsibility towards society, a point that is usually highlighted by the representatives of research funding organizations.

In Germany, the concept of responsibility is interlinked with the federal system of STI policy. Importance is given to cooperation between federal, state and institutional levels, since they all have a certain autonomy in structuring their activities. There is a demand by researchers to be provided with more open spaces for discussion and exchanges between the different policy levels and societal actors. This is important in the current conflict between the increasing application of quantitative standards in research evaluation processes, on the one hand, and the mainly qualitatively assessed inclusion of various stakeholders in the research process, on the other. The national research system does not take these inclusive aspects into the evaluation process, resulting in difficulties to correctly assess the impact of research and researchers. As such, evaluation criteria should be reassessed, opening up spaces for discussions in which topics and challenges can be reframed. The actual establishment of responsibility has to be done on the level of peer groups with a focus on the communication between different actors within the science system. A top down approach is not appropriate in this case, since there is a need to pursue a "cultural change" within research peer groups (NR Germany).

\section{Ethics in STI}

The ethics debate on STI in Germany is strongly influenced by medicine and the life sciences, as is the case in most nations. Since 1973, the establishment of ethics committees provides the most important institutionalized control procedures. Since the 1990s, consultation by an ethics committee has been mandatory by law in all medical research projects with people. These serve as internal scientific bodies of self-control and administration. As such, the basic structure of ethics committees has been adopted for the debate of major concerns at the national level. The central national institute is the German Ethics Council, established in 2001 and composed of 26 members specializing in scientific, medical, theological, ethical, social, economic and legal concerns result in connection with research and development (Ethics Council 2020). The Council formulates statements, recommendations and reports on various topics that serve as a basis for political decision-making. In addition to its advisory function, its task is also to promote a social debate, resulting in an increasing involvement of the public in its processes. Similar structures are evident in UK, France and the Netherlands but not in emerging STI powers such as China or India.

The focus of ethics discussions in Germany continues to be mainly on the life sciences, with a shift from directly human-related ethical issues such as the beginning and end of life, to socio-economic and socio-cultural issues, such as intersexuality or cost-benefit assessments. In addition to other classic topics such as animal experiments and military research, similar approaches are also being extended to other research topics: e. g. in 2011, a national ethics committee for safe energy supply was set up, which called for a nuclear phase-out, while in 2018, a national ethics committee for autonomous driving followed. This trend also reached other scientific disciplines and led to the establishment of corresponding committees and codes, among others in the engineering and social sciences. In view of this development, some scientists speak of an increasing "ethicization" of research (Bogner 2013).

\section{Despite the current debate \\ on the ethical aspects of progress, the main challenge remains its integration into practice.}

In addition to the establishment of advisory and controlling bodies, since the 1980s scientific institutes have increasingly been developing (interdisciplinary) research on social aspects of technology and technology ethics has become established as an independent discipline. This trend also resembles that seen in UK and Norway (NR UK; NR Norway). Despite the current debate on the ethical aspects of progress, the main challenge remains its integration into the practice. Above all, in view of ethics committees as a central instrument there is the danger of a pure 'checking box' approach, instead of actually discussing the consequences. In such a case, it would be mere enforcement without essence. A separate position takes up the question of internal research ethics and scientific integrity. Shaken by a particularly serious case of scientific misconduct, the German Research Foundation (DFG) issued scientific recommendations to ensure good scientific practice, whereby ombudspersons and commissions are used as central instruments to ensuring good practices (DFG 2019).

\section{Societal engagement in STI}

In terms of societal engagement, Germany's paradigm is not dissimilar to that of other advanced economies, although there is certainly difference in the development of the field with emerging economies such as China and India. Since the 1970s in western countries, the increasingly critical public, which expressed doubts about some technical developments, as well as about the self-controlling abilities and legitimacy of STI, laid the foundation for the current developments. In Germany, the first ever implementation of societal engagement in the official decision making took place in the early 1980 s as the task of a parliamentary (Enquête) Commission on Genetic Engineering in the Bundestag, while in the 1990s, the consultation of civil society 
groups became a standard instrument of the Commissions. Ever since, participatory activities have been normalised either in individual STI topics, or as a broad citizens' dialogue on the future of STI. One could argue that nanotechnology has become an important paradigm in this development, as it represents the first enabling technology that has included widespread societal engagement activities in most nations very early in the technology development trajectory (as opposed for instance to biotechnology where engagement was initiated at a much later stage in technology development). Examples are national initiatives on public dialogue or citizen consultation programmes attached to funding programmes for nanotechnologies in Germany, UK and France (NR Germany; NR UK; NR France). ity is better known and well-integrated in the national research system is due to the fact that it has been specifically developed as a tool for a more inclusive, transparent and social responsible research in the major national research organisations. As such, sustainability would not only be a very similar concept to that of RRI in its original conception, but it also allows its use as a definition of responsible STI in the national context in a more comprehensive fashion than RRI. In this manner, it is advisable to further investigate the uptake of responsibility in the national STI system by analysing closer the implementation of Sustainability vis a vis the various parameters of its application (e. g. key performance indicators). In addition, if ethics and societal engagement are a vital part of a responsible and sustain-

\section{It is advisable to further investigate the uptake of responsibility in the national STI system by analysing closer the implementation of sustainability.}

Recently, there has been a renewed effort to re-define the societal role that scientific organisations play via the pursuit of 'societal challenges'. This new approach has been adopted in organisational mission statements and funding programmes in Germany. It however still must be regarded a niche practice in the majority of research organisations (Hennen et al. in print). This is by no means unique to Germany though, as we see similar approaches in China (NR China), France (NR France), Australia (NR Australia) etc, with a similar divide between mission statements and actual practice. In Germany, it also takes the form of citizen science. From 2014 to 2016, the BMBF led comprehensive efforts to promote Citizen Science with the formulation of the Green Paper - Citizen Science Strategy 2020 for Germany, after 13 dialogue forums with more than 900 participants including (BMBF 2016).

Despite these efforts, a particularly critical point is the question of public involvement in the actual agenda setting. For instance, even the policy paper on participation in the HTS was formulated without much public involvement. Research organisations also tend to coordinate their research programmes directly with policy makers as elected representatives, without involving other representatives of civil society. There is thus the risk that actual inclusion of various stakeholder or citizen perspectives in official research policy will remain unattained.

\section{Discussion}

Based on the analysis of the national STI context in Germany and the comparisons with other countries, it is clear that Ethics and Societal Engagement are intrinsically related to responsibility and sustainability. The fact that the concept of Sustainabil- able STI, this is true not only in Germany but also in any other STI-intensive economy. Notwithstanding differences in political systems and decision making structures, these two concepts are evident in every national discourse and can potentially be used interchangeably in the STI debates. As such a future conceptualisation of RRI should be based closely on that of sustainability.

Moreover, coordination of action amongst countries in this field, is crucial. As the concept of RRI has been developed mainly within European Union STI projects, national comparisons is the preferable way to analyse and establish the underlying concepts at international level. Any further developments in the standardisation of ethics or societal engagement will also require multi-national or even global efforts and research project, that are coordinated centrally. We will not attempt to provide a specific recommendation about the location of such "central governance" structure. The UN system offers such opportunities (e. g. the UN Commission on Science and Technology for Development -UNSCTD, or the UN Educational, Scientific and Cultural Organisation -UNESCO) and so do big international funding programmes such as the Horizon Europe. In any case, the necessity to undertake such research actions is evident and the field is mature to move to a global level of activity.

\section{National Reports (NR)}

National reports issued in 2019 by the EU funded project (2016-2019)

Responsible Research and Innovation in Practice (RRI-PRACTICE) are available online at https://cordis.europa.eu/project/id/709637/results, last accessed on 28.10.2020.

Further information on RRI-PRACTICE is available online at https://cordis. europa.eu/project/id/709637 and at www.rri-practice.eu, last accessed on 28.10 .2020 


\section{References}

BMBF - Bundesministerium für Bildung und Forschung (2014): Die neue Hightech-Strategie. Innovationen für Deutschland. Available online at https://www.bmbf.de/pub_hts/HTS_Broschure_Web.pdf, last accessed on 15.05 .2020$.

BMBF - Bundesministerium für Bildung und Forschung (2016): Bundesbericht Forschung und Innovation 2016. Forschungs- und innovationspolitische Ziele und Maßnahmen. Available online at https://www.bundesberichtforschung-innovation.de/files/Publikation-bmbf_bufi_2016_hauptband_ barrierefrei.pdf, last accessed on 27.10.20.

Bogner, Alexander (ed.) (2013): Ethisierung der Technik - Technisierung der Ethik. Der Ethik-Boom im Lichte der Wissenschafts- und Technikforschung. BadenBaden: Nomos.

DFG - Deutsche Forschungsgemeinschaft (2019): Good research practice. Available online at https://www.dfg.de/en/research_funding/principles_dfg_ funding/good_scientific_practice/, last accessed on 13.05.2020.

EC - European Commission (2020): Responsible research \& innovation. Available online at https://ec.europa.eu/programmes/horizon2020/en/h2020-section/ responsible-research-innovation, last accessed on 28.10.2020.

Ethics Council (2020): The German ethics council. Available online at https:// www.ethikrat.org/en/the-german-ethics-council/\#m-tab-0-ourmandate, last accessed on 28.10.2020.

French National Assembly (2017): Resolution on science and progress in the French Republic. Available online at http://www.assemblee-nationale.fr/14/ ta/ta0926.asp, last accessed on 10.05.2020.

Hennen, Leonhard; Hahn, Julia; Ladikas, Miltos (in print): Competing modes of responsibility in research organisations. Insights from an international comparison. In: Science and Public Policy.

Ladikas, Miltos; Hahn, Julia; Hennen, Leonhard; Kulakov, Pavel; Scherz, Constanze (2019): Responsible research and innovation in Germany. Between sustainability and autonomy. In: Journal of Responsible Innovation, pp. 346-352. DOI: $10.1080 / 23299460.2019 .1603536$.

LeNa project (2016): Nachhaltigkeitsmanagement in außeruniversitären Forschungsorganisationen. Available online at https://nachhaltig-forschen. de/startseite/, last accessed on 12.05.2020.

Norway Research Council (2015): Strategy for innovation in the public sector. Available online at: https://www.forskningsradet.no/siteassets/ publikasjoner/strategy-for-innovation-in-the-public-sector.pdf, last accessed on 18. 05.2020.

Quartier Zukunft et al. (ed.) (2020): Dein Quartier und Du. Nachhaltigkeitsexperimente im Reallabor zu Nachbarschaften, Bienen, Naschbeeten, Kreativität und Konsum. Karlsruhe: KIT Scientific Publishing. DOI: 10.5445/ KSP/1000076132.

Schroeder, Doris; Rerimassie, Virgil (2015): Science and technology governance and European values. In: Miltos Ladikas, Sachin Chaturvedi, Yandong Zhao and Dirk Stemerding (eds.): Science and technology governance and ethics. A global perspective from Europe, India and China. Cham: Springer, pp. 53-71. DOI: 10.1007/978-3-319-14693-5_5.

Stilgoe, Jack; Owen, Richard; Macnaghten, Phil (2013): Developing a framework for responsible innovation. In: Research Policy, 42 (9), pp. 1568-80. DOI: 10.1016/ j.respol.2013.05.008

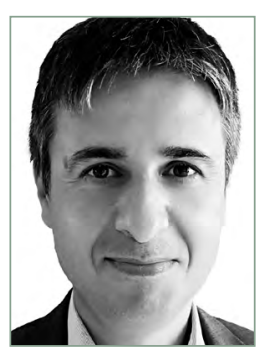

\section{DR. MILTOS LADIKAS}

has been at ITAS since 2013 with a research focus on ethics in STI policy and global TA. He was the Principle Investigator of the project RRI Practice.

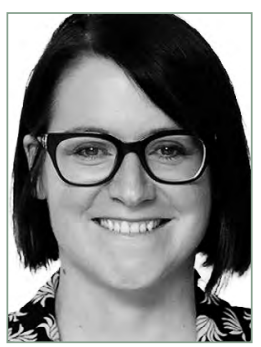

\section{DR. JULIA HAHN}

has been at ITAS since 2011 with a research focus on global TA, RRI and participatory TA methods. She was a member of the RRI Practice research team.

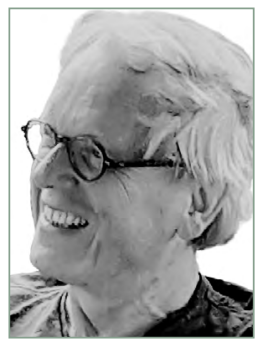

\section{DR. LEONHARD HENNEN}

is senior scientist at ITAS. He has been involved in several international projects on concepts and methods of TA and since 2005 co-ordinator of the European Technology Assessment Group (TA studies on behalf of the European Parliament). From 1991 to 2005 he was project manager at the Office of Technology Assessment at the German Parliament.

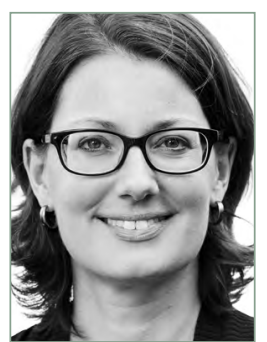

\section{CONSTANZE SCHERZ}

is the deputy director of ITAS. As a sociologist, she researches in particular the conditions for knowledge production in modern societies and conceptual questions of knowledge transfer. She worked on the EU funded project RRIPractice. 